\title{
A DESCOBERTA DA ÁFRICA SUDOESTE PELOS PORTUGUESES ( $\left.{ }^{\star}\right)$
}

"Cem quilômetros ao norte de Swakopmund, na Africa sudoeste, numa encosta escarpada, ergue-se uma grande cruz de pedra. Diante dela se estende a vasta imensidão de água do Oceano Atlântico. Atrás dela fica o êrmo deserto de Namib. Aos pés da cruz, sốbre os penhascos nus, milhares de focas tomam sol. Olhando para o sul, se pousa o olhar em salinas a perder de vista".

Com estas frases lapidares, como se fôssem esculpidas em mármore, começa a clássica obra histórica de nosso homenageado sôbre "A velha Africa sudoeste". Adicionemos ainda a primeira parte da primeira frase, com a qual se inicia a introdução:

"Sòmente deveria ler êste livro aquêle que aprecia a Africa sudoeste",

e assim acreditamos ter encontrado o melhor lema, que também deve servir para a seguinte exposição, baseada no estudo e no conhecimento do país.

A acima mencionada "grande cruz de pedra" (um pilar com brazão, em português "padrão", com uma cruz coroando a haste), foi

"o primeiro monumento do poder europeu em solo do sudoeste africano" (Vedder).

Foi erigido pelo português Diogo Cão (em latim Jacobus Canus) em sua segunda viagem de descobrimento (1484-1486), que o levou até a Cape Cross. Em 1893 o cruzador alemão Falke levou êste pilar para Kiel. Como estivesse muito desgastado, foi confeccionado um nôvo, nas medidas do antigo, provido do brazão do império alemão e por ordem do imperador Guilherme II, foi erigido em 1894, no mesmo lugar onde outrora estivera o português, o qual fôra entregue ao"Museu Oceanográ-

(*). - Este artigo consta duma publicaçāo em homenagem ao Dr. h. c. Heinrich Vedder. Texto alemão traduzido pelo Prof. Dr. Erwin Theodor (Nota à Redação). 
fico de Berlim. A coluna heráldica (1) portuguêsa mostra, na parte anterior do capitel, o brazão português (as cinco "quinas"). Os outros três lados (2) estão recobertos por uma inscrição latina contínua, em minúsculas góticas:

"A mundi creatione fluxerunt anni 6684 et a Christi nativitate 148 ? quum excelentissimus serenissimusque Rex d. Johanes secundus portugaliae per jacobum canum ejus. militem columnam hic situari jussit".

$\mathrm{Na}$ haste encontra-se, também em minúsculas góticas, uma inscrição portugụêsa, que, começando à esquerda sob o brazão, circunda a parte superior do cilindro e, pelo conteúdo, corresponde à latina.

Com a subida ao trono de D. João II, ressurgiram em Portugal os velhos planos do Infante D. Henrique (1394-1469). A intenção era prejudicar

"o comércio de Veneza com a abertura de um caminho maritimo direto às fndias Orientais. A costa oci-: dental da Africa serviu de indicação, certamente em quedireção deveria encontrar-se o fim do muro que separava o mar ocidental do oriental. Assim pois, navegaram confiantes os marinheiros portuguêses em direção. ao sul e erigiram com pilares e cruzes de pedra, em avancadas encostas escarpadas, os monumentos de sua bravura" (3). "Os navios de Diogo Cão voltaram a Portugal pelo mês de outubro de 1486. As noticias trazidas fortaleceram no rei D. Joăo II - como escreve N. Vedder (op. cit., p. 5) - a esperança de que uma nova expedição conseguiria alcançar a extremidade sul da África, dobrar o cabo e dessa forma abrir o caminho maritimo para as Índias".

(1). - o brazão de Portugal é, de há anos, o símbolo da atitude espiritual dêsse povo nas épocas cruciais de sua história. Também nas navegaçōes e descobrimentos dos Lusíadas flutuava a bandeira com as "quinas": cinco escudos azuis, colocados na forma de cruz e adornados com cinco esferas de prata, sendo o todo abrangido por um escudo maior, por sua vez circundado por sete tôrres de castelo. H. Rheinfelder, As Quinas de Portugal e Camōes. In Portugal 1140-1940; Festschrift der Univ. KöIn zu den portug. Staatsfeiern des Jahres 1940, Köln, 1940, pág. 150. - Diogo Cão foi o primeiro a levar tais padrões que, de acôrdo com a idéia de João II (1481-1495), eram levantados como símbolo do descobrimento e da tomada de posse, em lugar das cruzes de madeira, utilizadas pelos marinheiros de $D$. Henrique-o-Navegador.

(2) _- - Edgar Prestage, Die portugiesischen Entdecker, Lípsia, 1936, pág. 147.

(3). - Hans Meyer, Das Deutsche Kolonialreich, Lípsia, 1910, vol. II, págø. 131-132. 
Ravenstein (4) provou que já a 10 de outubro de 1486 Bartolomeu Dias fôra encarregado da chefia desta nova expedição. A partida deve ter-se dado entre fins de julho e comêço de agôsto de 1487 e o retôrno a 2 de dezembro de 1488. Nesta viagem Dias erigiu três novos pilares com o brazão português, dos quais porém só se conservaram fragmentos de um. Esste foi encontrado em 1786, nas proximidades da Baía de Spencer, nas costas do que depois viria a denominar-se a Africa sudoeste alemã. Mesmo que na ocasião ainda estivesse intacto, sua inscrição entretanto não mais podia ser decifrada. Quando foi procurado novamente, na primeira metade do século XIX, estava em ruínas, e os seus restos se encontram hoje na Cidade do Cabo e em Lisboa.

Infelizmente ainda não foi possível encontrar o relato de viagem original de Bartolomeu Dias. Por isso somos levados a aceitar a narrativa do historiador português do século XVI, João de Barros, tendo êle próprio estado na Africa sudoeste, e em cuja obra, Ásia (dec. I, lib. III, cap. 3) se lê o seguinte (5)

"Na viagem de retôrno conseguiram êles finalmente atingir o estranho cabo, que ficara por descobrir tantos séculos a fio, e por cujo contôrno foi aberto o caminho para uma parte do mundo. Bartolomeu Dias batizou-o de Cabo Tormentoso, devido às terriveis tempestades que tiveram de enfrentar na primeira vez que o dobraram. Entretanto, quando chegaram a Portugal, deu-lhe o rei o nome mais promissor de Cabo da Boa Esperança, pois êle alimentava a boa esperança de, uma vez contornado, encontrar o caminho para as Índias... Em dezembro de 1487 chegaram êles a Portugal, depois de terem levado 16 meses e 17 dias de viagem e descoberto uma costa de 350 milhas maritimas".

Com relação às datas exatas desta viagem, reportamo-nos aos já mencionados resultados das pesquisas de Ravenstein. Por mais incompleto que possa ser o relatório de João de Barros, é possível reconstruir grosso modo o desenrolar da viagem como prova Hennig (6) - pela comunicação de João de Barros, de que os nomes foram atribuídos de acôrdo com o santo do calendário do dia da descoberta. Dessa forma resulta aproximadamente o seguinte quadro:

(4). - E. G. Ravenstein, The voyages of Diogo Cão and Bartholomeo Diaz, 14811488. In Geographical Journal, vol. 16 (1900), pág. 628.

(5). - Cf. Richard Hennig, Terrae Incognitae, Leiden, 1956, vol. IV, pág. 429.

(6). - Idem, ibid., pág. 432 . 


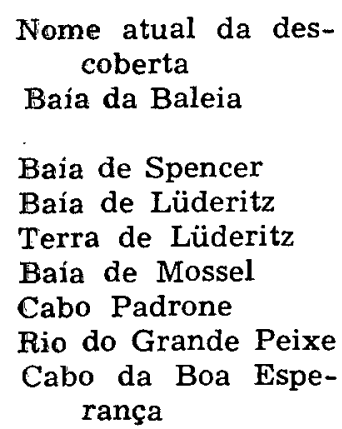

Nome original

Gôlfo de Santa Maria

Gôlfo de São Tomás

Gôlfo de Santo Estêvão

Terra de Silvestre

Baía de São Brás

Cabo de Padrone

Rio do Infante

Cabo das Tormentas
Data aproximada

8 de dezembro de 1487

21 de dezembro de 1487

26 de dezembro de 1487

31 de dezembro de 1487

3 de fevereiro de 1488

12 de março de 1488

meados de março

16 de agôsto de 1488

Compare-se esta atribuição de nomes, com a de Colombo para as regiões recém-descobertas, a realização de uma espécie de batismo cristão do Nôvo Mundo (por exemplo: El Salvador, Santa Maria de la Concepción, Trinidad).

As ruínas das colunas que Dias erigiu no dia de São Jorge, a 12 de março de 1488 (no Cabo Padrone, perto da Baía de Algoa), foram encontradas em 1938 (7). Foi o último marco da realeza portuguêsa por êle levantado. Dez anos mais tarde dirigiu êle, por ordem de seu rei, a construção dos dois navios maiores para a memorável viagem de Vasco da Gama que, com a descoberta do caminho marítimo para as fndias, coroou a obra do grande Infante D. Henrique. Em Angra Pequena, a atual Baía de Lüderitz, erigiu Dias, em altos penhascos (Pico Dias, de acôrdo com seu nome), uma cruz de pedra constituída de calcário de conchas, um marco distintivo do velho sudoeste da Africa (cf. a bela aquarela de Hans Busse em Hans Mayer, op. cit., p. 144).

Porém a cruz do Pico Dias é o monumento desta viagem, que trouxe pela segunda vez europeus para solo da África sudoeste. (H. Vedder, op. cit., p. 6).

$\mathrm{O}$ que deve ter levado aquêles portuguêses a empreender estas ousadas viagens de descobrimento, é assunto controvertido. Teria sido a procura de lucros, a luta por riqueza e poder, ou havia também motivos idealistas, um impulso de pesquisa científica e fé cristã? Do cronista oficial do Infante D. Henrique, Gomes Eanes de Zurara, em sua Crônica dos feitos de Guiné (1453), extraímos os seguintes motivos para os empreendimen-

(7). - Eric Alexon, o Padrão de João Filipe de Bartholomeu Dias. (Bol. Soc. Geogr., Lisboa, 1939, pág. 123, apud Egmont Zechlin, Maritime Weltgeschichte, Hamburgo, 1947, pág. 409. 
tos na Africa (8). Esfôrço por um maior conhecimento geográfico, expansão da fé cristã, estabelecimento do poder e das fronteiras do mundo árabe e o desêjo de relações comerciais, bem como ligação militar com os países supostamente cristãos na retaguarda dos mouros. Friederici (9) afirmou:

"As famosas viagens de exploração do português Infante $D$. Henrique, que cada vez mais desvendavam a costa da Africa sudoeste para os europeus, não foram mais do que viagens para a captura de escravos".

Este ponto de vista pode ser atualmente considerado como superado e desmentido. Richard Hennig (10) prova que Friederici pintou

"uma imagem deturpada do Infante", que "não corresponde à realidade".

Mesmo precisando admitir que o Infante D. Henrique

"não desprezou as consideráveis possibilidades de lucros, que o tráfico de escravos oferecia",

não se deve esquecer que na opinião da época a captura e tráfico de escravos (a Igreja o aceitava em sua bula de 1452) não constituiam profissão vergonhosa, mas aconteciam para glória de Deus, a fim de

"amadurecer os povos pagãos para a conversão ao cristianismo". "Se as suposições de Friederici tivessem qualquer validade, realmente teria o principe feito muito melhor se tivesse conservado para si suas rendas como príncipe e mestre da Ordem dos Cavaleiros de Cristo e renunciado à aparentemente pouco rendosa "caçada de escravos".

$\mathrm{Na}$ realidade tinha o príncipe, em primeira linha, interêsses espirituais, culturais e científicos mais elevados, a saber: o desvendar dos segredos do mar sombrio.

"Os portuguêses queriam procurar o reino do Prestes João (na Etiópia), a fim de a êle unidos, e partindo de lá atacarem os mouros" (11).

\footnotetext{
(8). - Apud Egmont Zechlin, Heinrich der Seefahrer und die Entdeckung von Negerafrika, in Afrikanist. Studien (Festschrift z. 80. Geburtstag von Diedrich Westermann), Berlim, 1955, pág. 19.

(9). - Georg Friederici, Der Charakter der Entdeckung und Eroberung Amerikas durch die Europäer, Stuttgart-Gotha, 1925, vol. I, pág. 307.

(10). - Rich. Hennig, op. cit., vol. IV, págs. 9-12.

(11). - Leopold von Ranke, Weltgeschichte, Lípsia, 1888, vol. IX-2, apud Hennig, op. cit., pág. 12 .
} 
Escrevi anteriormente (12) que me é difícil supor que uma vil cobiça e a busca de grandes lucros tenha sido a principal fôrça a impelir os portuguêses a êsses empreendimentos incrivelmente árduos e penosos. Estava e estou muito mais convencido de que tais feitos só são possíveis quando nêles existe uma grande fôrça moral, a crença em uma idéia, em uma missão divina, que também ajude a vencer as situações mais difíceis que se apresentam e que empresta tenacidade e auto-superação. $O$ fato de os portuguêses terem tido esta fé ardente em sua missão e de a terem realizado apesar de tôdas as dificuldades hoje dificilmente imagináveis, os tornou célebres para todos os tempos. Cf. René Maunier (Sociologie coloniale, Paris 19321942):

"Tous les anciens explorateurs ont cru qu'ils suivaient un appel de Dieu: un Christoph Colomb, un Vasco da Gama, un Fernand Cortes avaient leur astrologue et s'ils conduisaient, ils étaient conduits!" (13).

Encontrei uma confirmação do meu ponto de vista em Lisboa, no Congresso Internacional da História dos Descobrimentos, em setembro de 1960, realizado em honra do quingentésimo aniversário da morte do grande Infante. Em seu discurso de abertura salientou o presidente do Congresso (José Caeiro da Mata), que tôdas as viagens exploradoras dos portuguêses, que desvendaram a imagem do universo, aconteceram sob o signo da cruz cristã. No discurso de encerramento tratou o secretário geral do Congresso (Adriano Moreira) da grande atualidade do Infante D. Henrique. Teria êste, como o "Anjo da Guarda da Expansão", iluminado as viagens de descobrimento dos portuguêses, graças a seu alto valor ético, no qual se harmonizavam interêsses da Igreja e do Estado e que eram incentivados pelo traço fundamental universalista e humanista da história portuguêsa, refletidos de tempos imemoriais no "antiracismo" português.

Com isso retomou Moreira um pensamento, que também nas comemorações nacionais por ocasião do octogentésimo aniversário da existência de Portugal, em 1940, resumiu Mário de Albuquerque nas seguintes palavras:

(12). - E. G. Jacob, Das portugiesische Kolonialreich, Lípsia, 1942, pág. 115.

(13). - Apud E. G. Jacob, Chr. Columbus (Bordbuch-Briefe-Berichte). Bremen, 1956, pág. 349 .

(14). - Mário de Albuquerque, A capacidade épica da raça e o sentido camoneano das comemoraçōes centenárias, in Revista dos Centenários 1140-1940, ano II, n.o 15 (1940), págs. 1-3. 
"Pois êste foi o caráter de nossa história: lutamos contra todos os monstros com os quais a antigüidade povoava a infinidade do Atlântico. Pelos nossos esforços tornou-se maior e mais rico o Universo e o gênero humano se expandiu. Tornar-se infiel ao significado dos Lusiadas corresponde a trair a alma da Nação, à qual outrora o poeta Camões emprestou seu gênio". Assim, a "história camoniana" é também uma "política camoniana", ou seja, uma política da inteligência na luta contra o caos, um "política de espírito ordenador contra a lógica bárbara dos instintos".

No descobrimento da Africa sudoeste, precisamos ainda, finalmente, considerar a discutida questão da participação do alemão Martim Behaim. Nosso homenageado escreve (op. cit., p. 4):

"Vale a pena ainda mencionar que um dos conselheiros de Diogo Cão era o famoso cavaleiro português Martin Behaim, natural de Nuremberg".

Tratava-se de discípulo do astrônomo Regiomontanus, com o qual aprendeu, por meio de um astrolabium, a verificar, segundo a posição das estrêlas, o lugar em que se encontrava um navio, no vasto oceano. Emigrou êle para Portugal e acompanhou Diogo Cão em sua primeira viagem até o Congo. Existem porém fortes dúvidas de que tenha estado também no Cabo da Cruz. De volta a Nuremberg idealizou êle um globo terrestre enorme, onde constavam também as terras recém-descobertas da Africa. Estes registros estão corretos até o Congo. Depois dêle, porém, ou foram tirados de mapas mais antigos ou inventados livremente e não resistem a um exame científico. De qualquer maneira, devemos a uma observação em seu globo a notícia de que os navios com os quais êle viajou

"sempre para o sul e depois em direção leste (Gôlfo da Guiné) levavam consigo tôda sorte de mercadorias para o comércio com os nativos...".

$\mathrm{E}^{p}$ êste o ponto em que as modernas pesquisas históricas baseadas em seus resultados mais recente, introduzem complementações e emendas, mas, reconhecem também que o próprio Vedder era bastante criterioso, para, ao contrário de muitos de seus compatriotas, não sobrestimar os méritos de Martim Behaim (15). O primeiro a levantar dúvidas sôbre o fato de Mar-

(15). - Aproveito esta oportunidade para retificar em alguns pontos minha opiniāo, expendida anteriormente em desconhecimento da situação bas- 
tin Behaim sequer ter participado da viagem de Diogo Cão foi o geógrafo e historiador E. G. Ravenstein, cuja obra Martin Behaim, his life and his globe (Londres, 1908) ainda hoje é considerada a melhor biografia de Behaim. Enquanto na Crônica Mundial de Hartmann Schedel (Liber chronicarum cum figuris et imaginibus ab initio mundi, Nuremberg, 1493) ambos, ou seja, Diogo Cão e Martin Behaim são chamados de chefes da segunda viagem à Africa Ocidental, chegou Ravenstein, baseado em interpretação minuciosa da obra de Schedel, à opinião de que Martin Behaim tenha tomado parte em outra viagem, ̀̀ costa da Guiné, que

$$
\begin{aligned}
& \text { "deve ter servido mais à abertura de caminho para } \\
& \text { o intercâmbio comercial". }
\end{aligned}
$$

Compare-se a exposição de Vedder acima, concordante, neste ponto! O historiador português dos descobrimentos, Damião Peres (16), acatou esta teoria de Ravenstein. Também Otto Berninger (17) acredita serem muito convincentes os indícios da não participação de Martin Behaim nas viagens de Diogo Cão. Como principal testemunha apresenta êle o historiador português João de Barros e seu trabalho Da Ásia (Veneza, 1551), onde se fala apenas de uma única viagem de Diogo Cão e na qual não é citado Martin Behaim. Como relata João de Barros, Diogo Cão, em sua viagem de volta, deve ter navegado pelo Zaire (Congo) acima. Inscrições contemporâneas num penhasco perto da foz do Mposo, no Congo, mostram ainda hoje que êle deve ter chegado pelo menos até êste ponto (18). As inscrições contêm as armas portuguêsas e uma observação da qual se depreende que os navios do rei D. João II ancoraram lá. Além do nome de Diogo Cão estão gravados os de seus três companheiros mais importantes. Falta o nome de Martin Behaim, embora êle próprio afirme, numa inscrição em seu globo (1492) e em uma passagem na Crônica Mundial de Schedel, ter acompanhado Diogo Cão em 1484.

\footnotetext{
tante delicada das fontes e que sobreestimava a significação de Martin Behaim como navegador, principalmente nos meus livros: Das portugiesische Kolonialreich (Lípsia, 1942) e Cristoph Columbus (col. Dieterich, vol. 127, Bremen, 1956). No que respeita êste último último livro, cf. a resenha crítica de Heinrich Winter na revista Die Erde (ed. Sociedade Geográfica de Berlim), ano XC, págs. 370-371.

(16). - Damião Peres, História dos descobrimentos portuguêses, Pôrto, 1943.

(17). - Otto Berninger, Martin Behaim zur 500. Wiederkehr seines Geburtstages am 6. Okt. 1959, in Mitt. d. Fränk. Geogr. Ges., Erlangen, 1959, págs. 141-142.

(18). - Edgar Prestage, op. cit., págs. 147-148.
} 
A reabilitação de Martin Behaim, tentada por Hedwig Fitzler (19), considerando provas supostamente por ela encontradas em arquivos de notários e processos de Lisboa; mas perdidos na época da guerra, foi recusada pelos peritos Otto Berninger (op. cit., p. 146) e Richard Hennig (op. cit., p. 388), como insuficientemente fundamentadas. Heinrich Winter afirma:

\begin{abstract}
"Muita coisa não pode, tal como foi exposto, ter constado de processos civis, dando, pelo contrário, a impressão de pontos de vista subjetivos e não muito críticos. Baseia-se nesta fonte uma importante possibilidade de esclarecimento de algumas dúvidas". (In: Dt. Literaturzeitung, 1948, col. 236, Besprechung des Martin Behaim Globus).
\end{abstract}

Tôda esta problemática se agrava ainda mais pelo fato irrefutável de que Martin Behaim foi armado cavaleiro pelo rei português. Isto aconteceu a 18 de fevereiro de 1485. A suposição de que esta acolada tenha sido uma distinção aos méritos de Martin Behaim na viagem de Diogo Cão à Africa Ocidental já não pode ser sustentada. Uma vez que, de acôrdo com as pesquisas mais recentes (cf. O. Berninger, op. cit., pp. 144-145) uma participação de Martin Behaim na primeira viagem de Diogo Cão (1482-1483) não entra em consideração, mas que apenas pode ter participado da segunda que, de acôrdo com R. Hennig (op. cit., p. 386) começou em março de 1485 (que em Portugal ainda contava como 1484, cf. as datas do ano, freqüentemente trocadas no século XV: Hennig, op. cit., p. 385) e acabou em setembro-outubro de 1486, então a acolada só pode ter sido outorgada antes da particpiação de Martin Behaim na segunda viagem de Diogo Cão e portanto não se tratou de recompensa por esta viagem.

Um dos mais categorizados conhecedores da história das navegações, Heinrich Winter (20), levanta como uma das razões mais importantes contra a tese de participação de Martin Behaim o fato de se encontrarem sôbre o globo de Behaim inscrições, que constituem distorções tão flagrantes da realidade (assim a posição do Monte Negro, desviada em 22 graus!)

\footnotetext{
(19). - Hedwig Fitzler, Eine Ehrenrettung Martin Behaim. Die Fahrt mit Diogo Cão zur Walfischbuch 1485, in Fränk. Kurier, 11-VII-1935 e Der erste Deutsche in Südwestafrika? in Koloniale Rundschau, 1936, pág. 97.

(20). - Heinrich Winter, Der Behaim-Globus zu Nürnberg. Eine Faksimile-Wieder gabe in 92 Einzelbildern im Ibero-Amerikan. Archiv 1943, 1-2, in Deutsche Literaturzeitung, 1948, col. 231-236: Martin Behaim, Geschichte und Legende, in Die Erde, 1959, págs. 359-362.
} 
que não parece possível ter Martin Behaim, de acôrdo com Barros "orgulhoso de ter sido um discípulo" do célebre Regiomontanus, participado dessa viagem.

A êsse respeito afirma Götz Freiherr von Pölnitz (21):

"Baseado nessas divergências de opinião, já se duvidou ter o cidadão nuremberguês realizado mesmo a viagem ao Congo, pois de outra forma teria de ser admitida a hipótese de êle ter posteriormente alterado os resultados. Tal crítica, porém, vai demasiado longe. Uma época, na qual a mordacidade literária nada ocultava, teria sido certamente denunciada como falsas as afirmações de um homem, se êste, sem considerção pela inveja contínua que grassava entre os marítimos, cosmógrafos e conquistadores, se tivesse atribuído, sem motivos, a glória de descobrimentos. Seus relatos, por vêzes auto-suficientes, devem ter contido certos exageros, seja em virtude da notória vaidade dos humanistas, seja por enganos cometidos. Apesar disso tudo, porém, estava o rei $\mathbf{D}$. João II, a quem nada de importante passava desapercebido, certo do mérito do seu colaborador alemão. Como prêmio foi Behaim armado cavaleiro em 1485".

Heinrich Winter (22) provou que o Astrolabium já era em si conhecido desde longa data, tendo sido atestado já em 1482 na viagem marítima dos portuguses, e o quadrante mesmo em 1462. O (Jakobsstab?) (bastão de Jacó (?), conhecido já desde meados do século XIV, foi só adotado pelos navegadores portuguêses dois séculos após. As famosas Efemérides, escritas em latim, nada mais são que anuários astrônomo-astrológicos, em relação com a navegação. Em outro lugar menciona Winter (23) que, na obra portuguêsa, comemorativa do Jubileu, na História da Expansão Portuguêsa no Mundo (Lisboa, 1938, vol. I) ficou provado que Diogo Cão jaz enterrado em Portugal (na Catedral de Vila Real) e que, portanto, não morreu, como aponta o mapa-múndi de Henricus Martellus (24) na Africa, no ponto em que fôra decidido o retôrno, e dessa forma também Behaim não pode ter levado a esquadra de volta. Contrariando

(21). - Götz Frhr. v. Pölnitz, Martin Behaim, in Gehört - gelesen, 1957, págs. 744-752.

(22). - H. Winter, in Deutsche Literaturzeitung (Behaim-Globus), col. 234.

(23). - H. Winter, in Die Erde (Martin Behaim, Geschichte und Legende), 1959, pág. 300.

(24). - Henricus Martellus Germanus. Seu mapa mundi (constante do seu Insu1ário, posterior a 1489) ainda se baseia na concepção do mundo do Ptolomeu, mas estende os limites da mesma ao levar em têrmo de conta os descobrimentos de Bartolomeu Dias, englobando o Cabo da Boa Esperança; apud Lelträuser, Mappa Mundi, Berlim, 1958, pág. 178. 
ressa opinião, porém, provou Augusto César da Silva Castro Júnior (25), na sua mais recente contribuição para o Congresśo de Lisboa que, da legendá no mapa-múndi de Martellus, resulta que Diogo Cão morreu na Africa Ocidental. Seus ossos podem, portanto, ter sido levados apenas posteriormente a Portugal. Esta legenda reza o que segue:

"Ad hunc usque montem qui vocatur Niger pervenit classis segundi regis Portugalliae cujus classis prefectus erat Diegus Canus qui in memoriam rei. erexit columnam marmoream cum crucis in signo et ultra processit usque ad Serram Pardam que distat ab Monte Nigro mille miliaria et hic moritur".

De maneira filològicamente irrefutável traduz Silva Castro o hic moritur por morreu, que deve ser considerado um presente histórico (o presente expressa uma forma mais viva do aoristo). Como outro ponto de vista de importância em tôda a questão de Martin Behaim, deve ser considerado o que se segue. Nenhum escritor contemporâneo português mencionou Martin Behaim, o estrangeiro na Côrte Real portuguêsa, nem mesmo um cronista d'El Rei D. João II. Além da inveja, deve êste fato ter sido motivado também por naquela época tôdas as questões relativas à navegação e às viagens de descobrimento serem segredos de estado. O primeiro escritor português a mencionar Martin Behaim é o historiador João de Barros (14961570), cuja obra Da Ásia foi publicada em Veneza em 1551, e portanto 44 anos depois da morte de Behaim. Esta obra é, para nós, a única que afirma ter sido Behaim convidado a tornar-se membro da real Junta dos Matemáticos. Em época posterior, contudo, é freqüente e elogiosamente citado pela historiografia portuguêsa e espanhola. Assim diz R. Martins, in História das colônias portuguêsas (Lisboa, 1933):

"Na expedição que partira a continuar as descobertas mandara, talvez para experimentar as suas qualidades, o germânico Martinho da Boêmia, que se dizia discípulo de Regiomontano. Ia acompanhar Diogo Cắo, chefe da frota, e que levava os padrões basilares da posse" (26).

(25). - Augusto César da Silva Castro Jr., Diogo Cão e a legenda de Henrique Martelo, in Resumo das Comunicaçōes do Congr. Intern. de História dos Descobrimentos, Lisboa, 1960, págs. 28-32.

(26) - Devo esta indicação ao meu amigo português já falecido, o advogado Irarel Pott, que me forneceu juntamente com esse livro quando, depois de oito anos passados do nosso tempo comum de estudos em Coimbra. nos revimos em sua terra natal Lourenço Marques (Moçambique). 
E' de ressaltar-se, concluindo, que o problema Martin Behaim pode ser tratado apenas em breves anotações, isto é, na mais estreita ligação com o tema do descobrimento do sudoeste da Africa. Para que fôsse debatido todo o complexo das questões ligadas a Martin Behaim, teria de ser considerado. mais minudentemente um número muito maior de fatos históricos, assim como a sua participação na Junta dos Matemáticos, quartel-general secreto das navegações portuguêsas; a origem e o significado do seu globo (1492); o Regimento do Astrolábio (1484) e a carta de Hieronymus Münzer (1493). Sôbre a situação atual da pesquisa pọrtuguêsa em tôrno de Martin Behaim, escreveu minuciosamente Hermann Kellenbenz (27) . Cf. também o artigo Martinho de Boêmia, in Grant de Enciclopédia Portuguêsa-Brasileira (s. d., vol. IV, pp. 820821).

Considerando todo êste problema, inclino-me a aceitar a opinião defendida por von Pölnitz e Kellenbenz, de que

"os portuguêses, ao tentar rever a importância e o papel de Behaim, exageraram a verdadeira proporção da influência dêste" (Kellenbenz).

Mesmo considerando a "vaidade humanística", que caracterizou Martin Behaim, não será possível deixar de reconhecer ter sido êle o criador do primeiro globo terrestre conservado em nossos dias, que nos apresenta uma imagem do mundo tal como era concebida no início da época das descobertas. Isto tudo é verdade, apesar de não ter sido o grande astrônomo e cosmógrafo como o julgaram em épocas passadas. Com seu globo

"marcou o início do florescimento sucessivo da produção de globos em Nuremberg e no resto da Alemanha do Sul e mediante o mesmo conquistou lugar de honra. na história da cartografia" (Berninger).

Além disto deve Martin Behaim, como estrangeiro que era, ter-se destacado por "merecimentos notáveis", reconhecidos pela Côrte Real portuguêsa, pois de outra forma não teria recebido a acolada. Graças à elevada consideração em que o tinha o rei português, cresceram em importância os muitos alemães que então residiam em Lisboa. Antes e depois dêle, muitos dos seus concidadãos vieram a ali estabelecer-se, por exemplo, os Inhoff. Hirschvogel, Hochstetter, Holzschuher e Gossenprott. (27). - Hermann Kellenbenz; Portugiesische Forschungen und Quellen zur Behaim-Frage, in Mittlgn. d. Vereins f. Gesch. d. Stadt Nürnberg, 1958, págs. 79-95. 
Se Martin Behaim não tivesse sido tão viajado, o Imperador Maximiliano I não teria podido dizer:

"Martino Bohemo nemo unus imperii civium magis unquam peregrinator fuit magisque remotas adivit regiones" (28)

Referindo-se a isto, afirma von Pölnitz (op. cit.) :

"A inclusão daquelas notáveis reflexões, que levaram o comercialmente adestrado Maximiliano I a ligar-se, por meio de cidadãos do seu império, ao comércio português com as colônias, não pode deixar de ser cuidadosamente observada. E em nada opõe-se a esta realidade o fato de as chamadas criações coloniais dos Welser e Fugger na Venezuela, no Chile e no Perú ocorrerem ou serem completadas apenas uma geração depois de Behaim. Pois, apesar da distância em tempo, liga-se a concepção das casas comerciais do sul da Alemanha, lideres no intercâmbio comercial mundial, a homens do círculo regiomontano e de Behaim". "O reduzido número de fontes históricas para a biografia de Martin Behaim continuará sendo, por enquanto, o maior óbice para a pesquisa em tôrno de sua figura. De qualquer maneira, porém, sabese que Behaim chegou a Portugal na qualidade de comerciante, ai permanecendo durante a maior parte de sua vida (1459-1507). Casou com a filha do Governador da ilha dos Açores, Fayal, e morreu pobre, em Lisboa. Durante tôda a sua existência, porém, permaneceu estreitamente ligado à sua cidade materna, Nuremberg, e à sua pátria alemã. Com amplos motivos vemos nêle uma das grandes figuras de expressão alemã em Portugal, que sobreviverá no coração do povo alemão como o "cavaleiro com o globo" (30).

\section{ERNST GERHARD JACOB (31).}

(28). - Apud Fr. W. Ghillany, Geschichte des Seefahrers Martin Behaim, Nurembergue, 1853, pág. 75 .

(29). - Cf. E. G. Jacob, Deutschland und Portugal. Ihre kulturellen Beziehungen. Eine Bibliographie, Leiden (Holanda), 1961.

(30). - o "Instituto para a Cultura Alemã no Estrangeiro", fundado em 1951 em Dammstadt leva como título oficial o nome Martin-Behaim GeselIschaft, pretendendo estreitar os liames entre os alemães no estrangeiro e sua pátria e edita sua própria revista: Martin Behaim-Blätter.

(31). - Doutor em filosofia e historiador. Nascido em 1899 na cidade de Grim. má (Saxônia), estudou nas Universidades de Leipzig, Friburgo - em - Brisgóvia e Hamburgo, onde especializou-se em estudos luso-brasileiros, tendo mesmo publicado em 1927 um longo trabalho intitulado o movimento panibérico. Em 1958 refugiou-se na Alemanha Ocidental. As suas principais obras sāo Der Deutsche in Portugal und Spanien (1935), Das Portugiesische Kolonialreich (1942), Christoph Columbus (Bremem, 1956) e Alemanha e Portugal (bibliografia sôbre as suas relações culturais, incluindo a época colonial do Brasil (Nota da Redação). 